\title{
Educação em direitos humanos, drogas e redução de danos
}

\author{
Education in human rights, drugs and harm reduction \\ Educación en derechos humanos, drogas y reducción de daños
}

Rodrigo Alvarenga - Pontifícia Universidade Católica | Curitiba | PR | Brasil |

roalvarengafilosofia@gmail.com | https://orcid.org/0000-0001-8546-4442

Gabrielle Martignago Soares - Pontifícia Universidade Católica | Curitiba | PR | Brasil | gabrielle.martignago@pucpr.edu.br | https://orcid.org/0000-0002-9210-4928

Resumo: Essa pesquisa-ação buscou compreender a visão de adolescentes da periferia de Curitiba sobre a violência e o uso abusivo de álcool e outras drogas por meio de uma abordagem de educação em direitos humanos. O objetivo foi conhecer como a juventude exposta a um cotidiano de violência e drogadição vivencia e se expressa nessa realidade. Além disso, procurou-se avaliar se a educação em direitos humanos pode ser uma estratégia de redução dos danos sociais e psíquicos para adolescentes em territórios vulneráveis. Para isso, realizaram-se seis abordagens com os jovens e trabalharam-se temas relacionados a direitos humanos, drogas e violência. Como resultado constatou-se que a vulnerabilidade social atua como fator de angústia e sofrimento, principalmente sob o aspecto do racismo, e esse contexto potencializa os riscos para o uso problemático de álcool e outras drogas.

Palavras-chave: Direitos humanos. Drogas. Redução de danos.

Abstract: This action research sought to understand the view of adolescents from the periphery of Curitiba on violence and the abusive use of alcohol and other drugs through an approach to human rights education. The objective was to learn how youth exposed to a daily routine of violence and drug addiction experiences and expresses themselves in this reality. In addition, an attempt was made to assess whether human rights education can be a strategy to reduce social and psychological damage to adolescents in vulnerable territories. To this end, six approaches were taken with young people and themes related to human rights, drugs and violence were worked on. As a result, it was found that social vulnerability acts as a factor of anguish and suffering, especially under the aspect of racism, and this context increases the risks for the problematic use of alcohol and other drugs.

Key words: Human rights. Drugs. Harm reduction.

Resumen: Esta investigación-acción buscó comprender la visión de los adolescentes de la periferia de Curitiba sobre la violencia y el uso abusivo del alcohol y otras drogas a través de un abordaje de educación en derechos humanos. El objetivo fue conocer cómo la juventud expuesta a una rutina diaria de violencia y drogadicción vivencia y se expresa en esta realidad. Mas allá, se procuró evaluar si la educación en derechos humanos puede ser una estrategia de reducción de los daños sociales y psicológicos a los adolescentes en territorios vulnerables. Para ello se realizó seis abordajes con los jóvenes y se trabajó temas relacionados a derechos humanos, drogas y violencia. Como resultado se constató que la vulnerabilidad social actúa como factor de angustia y sufrimiento, principalmente en el aspecto del racismo, y dicho contexto aumenta los riesgos del uso problemático de alcohol y otras drogas.

Palabras clave: Derechos humanos. Drogas. Reducción de daños. 


\section{Introdução}

As violações dos direitos humanos associadas às questões que envolvem a produção, consumo e repressão às drogas ocorrem especialmente entre aqueles que, em função da desigualdade social, são marcados pelo Estado como indivíduos potencialmente perigosos. Isso tanto no que se refere à característica do grupo exposto à violência direta na guerra entre a polícia e o tráfico, como também no que diz respeito aos fatores de risco que podem fazer com que a experimentação dos psicoativos se tornem estados crônicos de dependência.

Entre esses fatores de risco podemos destacar a própria condição de pobreza que caracteriza o território onde essas pessoas habitam e a estigmatização a ele associado, bem como as frustrações relacionadas aos apelos da publicidade e dos ideais de uma sociedade de consumo, diante da qual o baixo poder de compra se torna o signo do fracasso. Além disso, existem outros fatores de risco que acentuam o sofrimento psíquico, na medida em que se caracterizam por uma existência fora dos padrões de normalidade da sociedade vigente, não apenas no que se refere à pobreza, mas também quanto aos preconceitos de gênero e de raça.

Nesse sentido, o estudo que se apresenta teve por objetivo compreender a realidade de um grupo de adolescentes e avaliar o potencial da educação em direitos humanos como estratégia de redução de danos à violência e ao uso de álcool e outras drogas. Partiu-se do pressuposto de que a educação voltada para as questões relacionadas às violações de Direitos Humanos que ocorrem no cotidiano dos jovens pudessem contribuir para o fortalecimento da subjetividade e o desenvolvimento da autonomia frente às situações que envolvem angústia, sofrimento e, por consequência, a propensão para o uso abusivo de álcool e outras drogas.

Constatou-se ao longo dos seis encontros realizados com os adolescentes um interesse latente pela temática dos direitos humanos e das violências relacionadas à questão das drogas. A correlação ficou evidente nos encontros, demonstrando que a educação em direitos humanos pode 
ser considerada uma estratégia de redução de danos ao uso abusivo de álcool e outras drogas, como também apontando para o impacto do racismo na saúde mental desses adolescentes, em sua maioria negros e moradores da periferia, que expressaram a falência da guerra às drogas e da política proibicionista como forma de prevenção.

\section{Procedimentos metodológicos ${ }^{1}$}

A presente pesquisa trata-se de um estudo de campo de natureza exploratória e qualitativa, embasada pela metodologia de Pesquisa-Ação e que se valeu da técnica de grupo focal para a coleta de dados. Segundo Thiollent (2005, p. 16),

a Pesquisa-Ação é concebida e realizada em estreita associação com uma ação ou com a resolução de um problema coletivo e no qual os pesquisadores e os participantes representativos da situação ou problema estão envolvidos de modo cooperativo ou participativo.

Os participantes selecionados foram adolescentes do Programa Jovem Aprendiz, com idade entre 15 e 18 anos, do Centro Educacional Marista Eunice Benatto, na região da Vila Torres, da cidade de Curitiba/PR. Foram realizadas seis abordagens com o grupo, nas quais foram trabalhados diferentes temas relacionados à educação em direitos humanos, drogas e violência, a partir de uma sondagem diagnóstica inicial sobre as expectativas dos adolescentes.

Após o levantamento inicial, foi desenvolvida uma proposta pedagógica que consistia na elaboração de minidocumentários produzidos pelos adolescentes com o objetivo de ampliar seus conhecimentos sobre direitos humanos, assim como sobre as drogas lícitas e ilícitas, por meio do diálogo e da informação científica.

Para isso, eles contaram com dois encontros de preparação e formação com relação à utilização de recursos audiovisuais que foram

\footnotetext{
${ }^{1} \mathrm{O}$ artigo é resultado do projeto de pesquisa $\mathrm{A}$ educação em direitos humanos como estratégia de redução de danos ao uso abusivo de álcool e outras drogas, que é uma parte da pesquisa mais ampla As múltiplas faces da violação dos direitos humanos no Paraná, aprovada pelo Comite de Ética e Pesquisa (CAAE): 78343617.5.0000.0020.
} 
propostos pelo Laboratório de Comunicação da PUCPR (LABCOM). Nesse momento, os adolescentes foram separados por grupos e um integrante de cada grupo ficou responsável por realizar a filmagem das atividades que ocorreram nos encontros seguintes.

O terceiro encontro foi realizado na forma de cine-debate, a partir da amostra de dois curtas-metragens, sendo "Morri na Maré" - acerca do impacto da violência na vida de crianças moradoras do Complexo da Maré, no Rio de Janeiro - e "\#meninapodetudo" - sobre machismo e violência contra a mulher na juventude.

No quarto encontro foi realizada uma roda de conversa a partir da escuta e análise de duas músicas escolhidas considerando os temas que mais se destacaram após o cine-debate, a saber: "P.U.T.A", da banda Mulamba, e "Crime Vai e Vem", do grupo Racionais MC's. Utilizou-se também a animação "Happiness", de Steven Cutts, para refletir sobre a questão da felicidade no mundo contemporâneo. No penúltimo encontro as equipes trabalharam na elaboração e formatação do vídeo, de forma que no último encontro cada grupo apresentou o resultado em um sarau cultural.

Para analisar as falas dos adolescentes utilizou-se Freud (2011), considerando a dinâmica da repressão do desejo, do sofrimento causado pela economia da libido e dos mecanismos de enfrentamento psíquico frente ao sentimento de culpa, tais como a arte, o conhecimento, o amor e a drogadição. A análise também se apoiou em Fanon (2008), para tratar dos efeitos psicológicos do processo de colonização e do racismo na constituição da subjetividade negra, que aumentam a vulnerabilidade dos jovens da periferia em face do uso abusivo de álcool e outras drogas. Além disso, utilizou-se de outros autores relacionados ao tema para discutir a relação entre racismo, guerra às drogas e psicanálise, entre os quais destacam-se Câmara (2012), Zamora (2012), Machado e Boarini (2013) e Karam (2013). 


\section{Políticas sobre drogas e redução de danos}

Segundo Machado e Boarini (2013), até a década de 1980, as ações de guerra às drogas praticamente anularam os investimentos em saúde pública e em prevenção, tratamento e reinserção social, concentrando toda a verba no campo da justiça e da segurança pública. A partir da segunda metade da década de 1980, com a comprovação da falência dessa estratégia diante do aumento da variedade e do consumo de drogas e com apoio dos movimentos sociais em prol dos direitos humanos, o Estado criou políticas públicas voltadas aos usuários de drogas, sejam lícitas ou ilícitas. O início da mudança das drogas para o campo da saúde pública se deu principalmente por conta da epidemia de Síndrome da Imunodeficiência Adquirida (AIDS) ao redor do mundo, sendo que só no Brasil, em 1997, foram registrados 22.593 casos.

Nesse contexto, as autoras explicam que as estratégias utilizadas eram as de redução de riscos - por meio da informação de práticas de sexo seguro, distribuição de preservativos e controle dos bancos de sangue - e as de redução de danos - voltadas para os usuários de drogas injetáveis (UDIs), por conta do compartilhamento e reutilização de seringas e agulhas - visando a redução do contágio e difusão do HIV (vírus da imunodeficiência humana) e da hepatite $B$.

De acordo com Machado e Boarini (2013), no Brasil, as ações tiveram início em 1989, na cidade de Santos/SP, onde se concentrava a maior parte dos casos de AIDS. Desde então a estratégia provocou polêmicas e resistências, pois opositores da abordagem alegavam que facilitava 0 consumo de drogas e gastava indevidamente o dinheiro público. A resistência aumentou após a aprovação da redução de danos como estratégia de saúde pública pelo então Conselho Federal de Entorpecentes. Os dois principais fatores para aprovação da redução de danos foram as respostas rápidas e eficazes obtidas contra a epidemia de AIDS e a execução dos direitos constitucionais garantidos pelo artigo 196 da Constituição Federal, o qual diz que o Estado tem o dever de garantir a saúde a todos, "devendo ser garantido por meio de políticas sociais e 
econômicas que visem a redução do risco de doença e acesso universal e igualitário as ações e serviços para promoção, proteção e recuperação" (BRASIL, 1988).

As autoras destacam que apesar dos conflitos com a Igreja, com as comunidades terapêuticas e a Polícia Federal, o Ministério da Saúde (MS), em conjunto do Programa das Nações Unidas para o Controle Internacional das Drogas, em 1994, reconheceu a redução de danos como estratégia de saúde pública no Brasil, tendo como meta a prevenção da AIDS, de Doenças Sexualmente Transmissíveis (DSTs) e da hepatite B entre UDIs. Em 2001, por meio da Lei Federal n 10.216/2001, legitimou-se a reforma psiquiátrica e garantiu as pessoas com transtorno mental o atendimento e tratamento da saúde mental no Sistema Único de Saúde (SUS), além de reconhecê-los oficialmente como responsabilidade de saúde pública.

Com a vigência desta lei, o investimento do Estado foi voltado para o tratamento e a reinserção social, priorizando as redes de cuidado extrahospitalares, como os Centros de Atenção Psicossocial (CAPS), além de ressaltar os direitos à saúde e à proteção do usuário e dependente de álcool e drogas. Em outro momento, o MS criou a Política de Atenção Integral a Usuários de Álcool e Outras Drogas, colocando a estratégia de redução de danos como pilar deste programa, fazendo críticas ao ideal de abstinência, de políticas proibicionistas e alertando para a responsabilidade da saúde pública pelo problema das drogas e pela necessidade de superar-se os modelos vigentes de intervenção e tratamento.

Apesar da validação da estratégia de redução de danos por meio das leis e políticas públicas, Machado e Boarini (2013) ressaltam que as resistências encontram-se divididas entre aqueles que se recusam a aceitar a validade no âmbito da prevenção, sob o pretexto de que a estratégia não foi validada cientificamente, e aqueles que a aceitam parcialmente, apenas se a RD buscar prevenir a AIDS e tiver como meta final a abstinência. $O$ primeiro posicionamento é pautado em valores morais, uma vez que não concebem o uso de drogas como necessidade ou desejo e classificam o usuário de drogas como 
[...] drogado, [...] um afastado de Deus, um ser possuído por satanases, $[. .$.$] uma vítima de um cérebro doente que perdeu toda$ a capacidade de autodeterminação. Um sujeito sem subjetividade que precisa ser sequestrado, reprogramado segundo procedimentos baseados na abstinência prolongada e reengenharia da vida (LANCETTI, 2015, p. 34).

No momento, o país vivencia um período intenso de reformulação de políticas públicas, sendo um dos maiores afetados os CAPS, por conta do direcionamento de dinheiro público para as comunidades terapêuticas. Em adição, em 2017, o Conselho Federal de Psicologia, o Mecanismo Nacional de Prevenção e Combate à Tortura e a Procuradoria Federal dos Direitos do Cidadão do Ministério Público Federal realizaram uma inspeção em vinte e oito (28) comunidades terapêuticas nas cinco regiões do país, encontrando diversas formas de violações de direitos.

Os tratamentos corretivos aplicados nessas comunidades eram diversos, como banhos de água fervente e gelada, laborterapia (trabalhos forçados e sem remuneração), choques insulínicos, uso de internações involuntárias e compulsórias com ausência de laudo médico e de comunicado ao Ministério Público, violação à liberdade religiosa e sexual, internação sem prazo de término, internação de adolescentes, violência física, indícios de tortura, isolamento e restrição do convívio social (incomunicabilidade com a família, visitas restritas, difícil acesso ao local, muros, portões, trancas e restrições à saída etc.), dentre outras inúmeras violações de direitos. Ocorre, portanto, um movimento de retorno às velhas concepções psiquiátricas baseadas na moral, na religião, na exclusão, no controle e representam uma ameaça para a Reforma Psiquiátrica Brasileira.

Ainda assim, no ano de 2019, foi assinado o Decreto n 9.761/2019 que estabelece uma Nova Política Nacional sobre Drogas. Esta Nova Política prevê que ações, programas, projetos de cuidados, prevenção e reinserção social deverão visar à abstinência em relação ao uso de drogas, descartando a estratégia de redução de danos. Neste mesmo decreto, reconheceu-se as comunidades terapêuticas como forma de cuidado, acolhimento e tratamento do dependente químico. Dessa forma, diminuirá ainda mais o 
investimento no setor público, no que tange à saúde mental, e aumenta-se no setor privado, para as comunidades terapêuticas.

Gehring (2014) realizou um levantamento por meio de entrevistas realizadas com cinquenta (50) residentes de uma comunidade terapêutica de Bauru/SP. Constatou-se que a maioria (72\%) está buscando a recuperação pela quarta vez (20\% está na segunda internação, 24\% na terceira e $28 \%$ na quarta). Um pequeno número de cinco pessoas (10\%) buscava a recuperação por mais de 10 vezes, sendo que um deles estava internado pela vigésima vez. É clara a ineficiência do método de abstinência, não apenas estatisticamente, como principalmente do ponto de vista da saúde mental e da garantia de direitos humanos.

Queiroz (2001) ressalta que a estratégia de redução de danos é mais do que uma alternativa à abstinência no tratamento da dependência e da prevenção do HIV/AIDS, ela também é uma estratégia de prevenção dos problemas relacionados ao uso abusivo de álcool e outras drogas. Sanchez (2017) descreve que prevenção pode ocorrer em três níveis: primária, destinada a sujeitos que nunca fizeram uso de drogas, com foco em evitar a experimentação inicial; secundária, destinada a sujeitos que fazem uso ocasional de drogas, com foco em evitar que o uso se torne abusivo e problemático; e terciária, destinada a usuários que já apresentam uso problemático.

Diante disso, faz-se necessário inserir o sujeito na elaboração das formas de tratamento, fazendo-o anunciar quais aspectos da sociedade o levaram ao consumo abusivo de álcool e outras drogas. Neste caso, a estratégia de redução de danos aborda com o usuário sobre os comportamentos de risco e os danos relacionados a ele, pois "o importante não é se determinado comportamento é bom ou ruim, certo ou errado. [...] a ênfase é se o comportamento é seguro ou inseguro, favorável ou desfavorável" (QUEIROZ, 2001).

Sendo assim, a redução de danos concentra-se no que funciona e no que ajuda do ponto de vista do sujeito, buscando alternativas de minimizar os malefícios causados pelo uso abusivo de álcool e outras drogas. Guiando- 
se sempre pelo respeito à liberdade de escolha do usuário de deixar ou diminuir o uso e de garantir que os riscos decorrentes deste sejam minimizados.

\section{0 mal estar na civilização e o fenômeno da drogadição}

Freud (2011), ao verificar a impossibilidade de responder à questão do propósito da vida humana, direciona seus estudos a uma questão menos grandiosa: O que os seres humanos querem da vida e o que desejam nela realizar? Para ele, as pessoas "buscam a felicidade, querem se tornar e permanecer felizes" (p. 19). Sendo isso determinado, seu propósito e intenção de vida e seu comportamento no mundo externo será determinado pelo princípio do prazer. Entretanto, as possibilidades de felicidade e prazer são limitadas, visto que o princípio de realidade imporá restrições ao desejo, proporcionando a vivência da infelicidade. Segundo Freud (2011), o sofrimento é experienciado por meio de três fontes: o próprio corpo, que é finito e limitado; o mundo externo, que ocasionalmente volta-se contra si; nos relacionamentos com outros sujeitos, que é o sofrimento mais doloroso do que qualquer outro.

Para Freud (2011, p. 18), "a vida, tal como nos coube, é muito difícil para nós, traz demasiadas dores, decepções, tarefas insolúveis". Com a finalidade de suportar essa experiência de sofrimento, o autor aponta que o indivíduo faz o uso de três mecanismos de enfrentamento: derivativos poderosos, que distrai da dor e da decepção; satisfações substitutivas, que as diminuem; e, substâncias tóxicas, que as tornam entorpecidas.

Por meio do deslocamento da libido, alguns indivíduos sublimarão através da arte, porém, Freud (2011, p. 24) classifica esse método como fraco, pois "ele pressupõe talentos e disposições especiais, que não se acham presentes em medida eficaz". Outros indivíduos irão sublimar através do isolamento da civilização, uma vez que consideram a realidade como inimiga e recriar-se-á outro mundo no qual os aspectos insuportáveis serão eliminados e substituídos por outros adequados aos seus desejos. Para Freud (2011, p. 25), quem se aventura nesse "caminho para a 
felicidade, normalmente nada alcançará $[\ldots]$ ", logo "torna-se um louco, que em geral não encontra quem o ajude na execução de seu delírio".

Há ainda indivíduos que irão deslocar sua energia para os relacionamentos no mundo externo com outros indivíduos. Esse mecanismo colocará o amor como centro de tudo e toda a satisfação no ato de amar e ser amado. O amor "proporcionou a mais forte experiência de uma sensação de prazer avassaladora, dando-nos assim o modelo para nossa busca de felicidade" (FREUD, 2011, p. 27). Todavia, Freud ressalta que nunca se encontra o indivíduo em um estado tão indefeso contra o sofrimento quando amando e tão infeliz ao perder seu objeto amado ou o seu amor.

Os relacionamentos com pessoas próximas, com fontes de auxílio, com objeto sexual de outra pessoa, com membro de uma família ou de um Estado são regulados pela civilização por meio da justiça, da lei e da moralidade. Tendo início com a proibição da escolha incestuosa do objeto de prazer, seguida pela restrição de escolha do objeto de prazer, devendo ser voltada apenas para o sexo oposto, e as satisfações extragenitais proibidas e consideradas como perversão. As proibições e a exigência de um único tipo de vida sexual para todos não levam em consideração as particularidades entre os indivíduos. O próprio amor heterossexual, proscrito pela sociedade, é limitado a monogamia e a legitimidade do casamento, então "se torna assim, fonte de grave injustiça" (FREUD, 2011, p. 50).

Levando em consideração os impedimentos colocados pela civilização para alcançar a felicidade e o como a vida por si só é difícil demais para o indivíduo, Freud (2011, p. 21) esclarece que:

[...] os métodos mais interessantes para prevenir o sofrimento são aqueles que tentam influir no próprio organismo. Pois todo sofrimento é apenas sensação, existe somente na medida em que o sentimos, e nós o sentimos em virtude de certos arranjos do nosso organismo. 
Dessa forma, o método da intoxicação é o mais eficaz em exercer essa influência no organismo, pois a substância promove sensações prazerosas e inibe a sensibilidade, a ponto de o sujeito não receber impulsos desagradáveis.

De acordo com a Organização Mundial da Saúde (OMS), droga é toda a substância que afeta a estrutura e o funcionamento do organismo. Encontra-se atualmente diversas classificações acerca dos tipos de drogas, variando entre as propriedades farmacológicas, os efeitos no organismo e a percepção dos usuários. Fonte (2006) cita que as classificações mais usadas na área da saúde dividem as drogas em: depressoras, que atuam no Sistema Nervoso Central (SNC), provocando relaxamento e diminuindo sensações dolorosas; estimulantes, que ativam o SNC, aumentando o estado de alerta, reprimindo sono e apetite; alucinógenas ou modificadoras, que provocam uma alteração no estado mental, gerando alterações cognitivas e perceptivas.

Câmara (2012) esclarece que apesar das proibições e exigências da sociedade serem menores atualmente, o sofrimento ainda se faz presente. Para se afastar dessa realidade, o sujeito faz uso de "mecanismos de fuga - sendo um desses mecanismos o ato da drogadição, que se tornou atualmente uma forma privilegiada de garantir gozo" (p. 54). O autor cita que proporciona ainda uma produção imediata de prazer, bem-estar e relaxamento das vivências conscientes, independência do mundo externo e refúgio num mundo próprio. Essas mesmas propriedades caracterizam seu perigo e seu potencial de causar danos ao indivíduo, uma vez que acarreta o desperdício de uma grande quota de energia libidinal que poderia estar sendo empregada para o aprimoramento das relações humanas.

O uso contínuo dessa substância pode levar a uma situação de dependência. Segundo Nogueira Filho (2002), a chamada toxicomania é a condição de existência de um sujeito cujas relações privilegiadas de prazer são operadas pela presença ou ausência de substância de efeito psíquico. Câmara (2012) destaca que ainda é capaz de ocasionar sintomas físicos e 
psicológicos e o sentimento de incapacidade de afastar-se da substância, mesmo que a experiência seja devastadora.

Fonte (2006) e Câmara (2012) ressaltam que o consumo da droga não torna o usuário automaticamente um toxicômano, uma vez que o uso não tem somente por finalidade causar alterações no organismo. Cada sujeito possui um modo de viver e uma relação com a droga, visto que existem sujeitos que fazem uso de drogas sem necessariamente serem dependentes, entretanto, apresentam uma grande dificuldade em viver em sociedade sem o apoio de uma substância.

\section{Guerra às drogas, racismo e subjetividades marginais}

O proibicionismo em relação às drogas ilícitas levou à pregação de um ideal de abstinência, como estratégia de evitar riscos e danos à saúde, que é "tão inútil quanto a proposta de abstinência sexual como forma ideal de evitar doenças sexualmente transmissíveis ou gravidez indesejada" (KARAM, 2013, p. 33).

Esse ideal se transformou em uma política de intromissão estatal na liberdade individual, com intervenção do sistema penal sob os produtores e distribuidores de drogas ilícitas e na declaração de uma "insana e sanguinária guerra" (KARAM, 2013, p. 34). Sustentada no poder bélico e pautada pelo punitivismo, Karam aponta que a guerra às drogas destrói vidas, espalha violência, mortes, prisões, estigmas, doenças e não obtém nenhum resultado significativo, pois não acaba com o consumo e a produção, tampouco reduz a circulação de drogas ilícitas.

Os comentários dos adolescentes sobre o documentário utilizado no cine-debate expressam essa realidade: 
[...] O Morri na Maré retrata bastante a nossa Vila, que é os olhos fechados para o ambiente que vivemos [...]. [...] A Polícia quando chega lá, ela não quer saber quem é bandido [...]. [...] Tempo atrás que morreu pessoas inocentes porque a Polícia chegou atirando e depois perguntando, exatamente como o que aconteceu no Morri na Maré. (informação verbal)²

[...] A questão da violência na favela é uma coisa que é muito complicada porque [...] a maioria das pessoas pensam que quem é bandido é 'os traficante' que 'tá lá' na favela, mas eles tão lá, eles conseguiram tudo aquilo, graças aos grandões que trouxeram a droga pra eles. Então eles são só mais uma vítima do sistema. Meus dois irmãos foram assassinados por conta de tudo o que rolou no sistema, entende? Então isso é tudo muito forte na nossa vida. Quem é da favela, mulher negra, é muito forte na nossa vida essa realidade. (informação verbal) ${ }^{3}$

Karam (2013) explica que essa instituição não é abalada pelas mortes e prisões, pois o dinheiro que gira em torno da repressão e da proibição cria indivíduos interessados em entrar nesse mercado, não somente para preencher o vazio dos que estão mortos ou encarcerados, como também para obter o mínimo para se viver. O Estado, em nome da guerra, precariza a vida desses sujeitos, colocando-os em uma situação de miséria, péssimas condições de vida e de privação de direitos básicos.

A autora destaca que a guerra divide as pessoas em "boas" ou "más", em "criminosos" ou "cidadãos de bem". A guerra cria o outro, o inimigo, um sujeito estranho e perigoso, desprovido de direitos, de dignidade, que perde sua qualidade de ser humano. A guerra não se dirige contra a droga por si só, ela volta-se às pessoas, sejam produtores, distribuidores ou usuários. "Os "inimigos" nessa guerra são os pobres, os marginalizados, os desprovidos de poder" (KARAM, 2013, p. 41).

Eu não moro na vila, né, e antes de eu começar a estudar no Manoel Ribas eu tinha muito preconceito. Quando eu, meu pai e minha mãe 'ia' ali no Habbib's, nossa, meu pai tinha muito medo do carro ser assaltado. Se a gente vinha de ônibus então, nossa, a gente ia no ponto ali da vila, nossa, tremia, morria de medo. Falava: "que lugar perigoso essa favela". Quando a minha mãe me colocou 'pra' estudar no Manoel Ribas, as 'minhas tia' 'falou': "você é louca, colocar essa guria dentro da favela, 'cê' vai perder ela pra estudar com esse bando de favelado". E quando eu entrei ali eu vi que foi a melhor coisa que a minha mãe fez porque eu descobri outra realidade e as minhas verdadeiras amizades eu fiz dentro da favela e as pessoas

\footnotetext{
${ }^{2}$ Relato do adolescente G., morador da Vila Torres, fala transcrita do cine-debate realizado no dia 23 de maio de 2019.

${ }^{3}$ Relato do adolescente N., fala transcrita do cine-debate realizado no dia 23 de maio de 2019.
} 
que eu mais gosto tão dentro da favela. E agora eu amo a favela. (informação verbal) ${ }^{4}$

[...] Quando passei a ter esse convívio com outras pessoas que estão relacionadas a periferia, eu vi que não é daquele jeito que a mídia mostra 'pra' nós, que é totalmente diferente, a gente é totalmente alienado. A gente é manipulado pelas mídias, pela internet, pela televisão [...]. (informação verbal) ${ }^{5}$

O reflexo disso é encontrado no sistema penitenciário. Segundo dados do Departamento Penitenciário Nacional (DEPEN), em 2017, a população prisional brasileira era de 726.354 pessoas, sendo 349,78 pessoas presas para cada 100 mil habitantes. 54\% destas pessoas são jovens entre 18 e 29 anos de idade. Destas 726.354 pessoas, 152.131 estavam encarceradas por conta de drogas (Lei n.0 6.368/76 e Lei n.0 11.343/06) e 461.961 pessoas $(63,6 \%$ da população prisional total) são negras e pardas, conforme Santos et al. (2017). O alvo da guerra às drogas é inconfundível: a população jovem negra.

Damasceno e Zanello (2018) ressaltam que os sujeitos negros têm seu sofrimento psíquico potencializado pela guerra, pelo racismo, pela violência, pelas precárias condições de vida e pelas constantes violações de direitos. Os impactos na saúde mental são inúmeros, como estresse, angústia, depressão, ansiedade, ataques de raiva, dificuldade de criação de vínculos sociais e emocionais, comprometimento da identidade e distorção do autoconceito.

Identifica-se, então, as três fontes de sofrimento propostas por Freud (2011): o próprio corpo, atrelado ao negativo, carregado de atributos pejorativos; o mundo externo, com a guerra, a violência estatal, a não garantia de direitos e a desigualdade social e racial; e no relacionamento com outros homens, por meio do racismo e do estigma.

\footnotetext{
${ }^{4}$ Relato do adolescente M., fala transcrita do cine-debate realizado no dia 23 de maio de 2019.

5 Relato do adolescente L., fala transcrita do cine-debate realizado no dia 23 de maio de 2019).
} 
Eu tive que amadurecer muito rápido, então, não sou aquela pessoa assim que, sabe, aproveita a vida igual um adolescente, pensa em coisas de adolescente. Eu não tive a oportunidade de ter essa fase. Muitas coisas me obrigam a ser adulta. Eu tenho que cuidar da minha mãe, eu tenho que pensar em problemas que eu não deveria pensar e isso me afetou de uma forma muito forte porque agora a minha saúde... Eu tenho dificuldades até 'pra' chorar, eu tenho que ir 'no' psicólogo, tenho que tomar remédio 'pra' ansiedade porque eu tive que ser adulta antes do tempo. Eu sinto que o mundo cobra muito de mim e isso é horrível. É muito horrível você ter que crescer antes do tempo, sabe? Você tem muito peso em cima de você. Tem horas que eu sinto que não consigo nem respirar, às vezes eu só quero um momento 'pra mim' ficar sozinha, assim, sem problema algum, sabe? Às vezes eu vejo a pessoa falando bem assim pra mim: "ai, minha mãe brigou comigo porque eu não posso fazer isso", "ai, minha mãe brigou comigo pra 'mim' ir pra escola", sabe? Eu nunca tive isso. Eu nunca tive minha mãe brigando comigo pra 'mim' ir pra escola. Eu nunca tive uma mãe que lavou roupa pra mim, que fez comida pra mim, pra eu chegar a ter probleminha de adolescente, entende? Então eu acho que essa é uma das coisas que... também fizeram bem 'pra' mim como pessoa, sabe? Mas também me afetaram demais. (informação verbal) ${ }^{6}$

Ao se construir a visão pejorativa do próprio corpo, ele deixa de ser uma fonte de alegria, uma vez que "o conhecimento do corpo é unicamente uma atividade de negação. É um conhecimento em terceira pessoa. Em torno do corpo, reina uma atmosfera de incertezas" (FANON, 2008, p. 104). Então "se estabelece uma relação persecutória entre o negro e o seu corpo" (ZAMORA, 2012, p. 567), logo buscar-se-á esconder todas as características negras dadas como ruins e feias. O negro buscará chegar o mais próximo possível do belo e bom, ou seja, busca assemelhar-se com o branco, embranquecer-se, e assim perdendo sua subjetividade, sendo autor de sua própria extinção.

O mundo externo, por meio da guerra às drogas, transforma o negro em "inimigos internos a serem caçados e combatidos" (ZAMORA, 2012, p. 568). Por sua vez, o Estado falha em garantir direitos básicos, como acesso à educação, bem como assistência e permanência nas escolas e universidades, saúde e moradia, principalmente nos locais majoritariamente ocupados por pessoas negras e atingidos pela violência. Sendo assim, "as formas preconceituosas de ver reduzem as oportunidades dos negros em vários campos da garantia de direitos e cidadania" (ZAMORA, 2012, p. 570), fazendo com que a população negra vivencie

\footnotetext{
${ }^{6}$ Relato do adolescente N., fala transcrita do cine-debate realizado no dia 23 de maio de 2019.
}

REU, Sorocaba, SP, v. 46, n. 2, p. 425-446, dez. 2020 
[...] em quase todas as dimensões de sua existência, situações de exclusão, marginalidade e/ou discriminação socioeconômica, o que a coloca mais vulnerável aos agravos à saúde e a faz adoecer de doenças curáveis e morrer antes do tempo, de mortes evitáveis (ZAMORA, 2012, p. 571).

Os sujeitos negros têm seus desejos pulsionais impedidos de serem satisfeitos por essa realidade marcada pela violência, pela desigualdade, pela violação de direitos, dentre outros. Karam (2013) aponta que eventualmente podem encontrar na droga uma maneira de lidar com o malestar e o sofrimento que Ihe é causado pela sociedade. Observa-se essa questão na entrevista realizada entre os próprios adolescentes:

Adolescente G.: Como que é sua vida na comunidade sendo negro?

Adolescente P.: Ah, é bem difícil, eu sou diferenciado das pessoas. G.: $E$ em outros lugares? Por exemplo, festas. P.: Em outros também. Por minha cor, eu sou... eu sou... Ahhh... G.: Pelo jeito que você se veste também? P.: Pelo jeito que eu me visto não porque é igual a todo mundo, eu me visto tipo padrão, quase todas as pessoas se vestem igual a mim.

G.: E tipo no shopping?

P.: No shopping sim, é diferente né 'as roupa' que eu me visto, tipo óculos, boné, calça caindo, o jeito que eu falo o palavreado.

G.: E em relação a tudo isso? Pelo jeito que você vai... porque é o seu jeito né, todo mundo tem que ter respeito, é o mínimo que tem que ter é o respeito. Como você se sente vendo as pessoas reagindo a você pelo jeito que você é?

P.: Eu me sinto mal né só porque eu sou de uma cor diferente eles agem assim comigo.

G.: E como você sente essa desigualdade social? Tipo, de você ter menos dinheiro que alguém do shopping, por alguém que vai no shopping que tem mais dinheiro que você, ser de uma classe social mais alta que você. Como você se sente em relação a isso?

P.: Eu me sinto mal porque só porque eles são 'boy', tem dinheiro e essas 'fita', eles acham que podem desmerecer eu, só por causa da minha cor, do jeito que eu me visto, do jeito que eu falo...

G.: Engajando nisso, em relação a sua cor, como você se sente vendo as pessoas reagindo ao seu jeito?

P.: Ah, não sei... Só acho que todo mundo tinha que agir normal comigo, não só por causa da minha cor ser diferente. (informação verbal) ${ }^{7}$

O ato da drogadição é a consequência de uma situação social ou familiar inadequada que, no primeiro encontro com a droga, acaba sofrendo seu "primeiro trauma psíquico" (CÂMARA, 2012, p. 54). O autor considera ainda que as circunstâncias da vida do sujeito podem favorecer esse

\footnotetext{
${ }^{7}$ Entrevista realizada pelo adolescente G. com adolescente P., transcrita do encontro realizado no dia 13 de junho de 2019.
} 
encontro com a droga, como o período vulnerável da adolescência. Na entrevista entre os adolescentes é possível observar as angústias e sofrimentos relacionadas à sociedade de consumo e à desigualdade social, visto que o incômodo com tal situação se expressa de forma gritante quando se fala do poder de compra das classes sociais mais altas "boy". Contudo, o mais intrigante é o modo como o adolescente explica que mesmo atendendo aos padrões de consumo em suas vestimentas e acessórios, segue a cor um fator determinante de exclusão. Ou seja, na fala do adolescente transparece a dinâmica do sofrimento psíquico relacionada ao racismo e à pobreza.

De acordo com Freud (2011), o propósito de vida dos homens é a busca pela felicidade, porém as possibilidades são limitadas devido aos impedimentos colocados pela civilização. O racismo e a pobreza são fatores de aumento exponencial do sofrimento na vida dos jovens moradores da periferia, uma vez que a experiência da infelicidade e da frustração, próprias da condição humana, são acentuadas pela realidade de violência e negação dos direitos humanos ao qual encontram-se submetidos.

A arte, o conhecimento e a cultura também são formas de lidar com a experiência do mal-estar, entretanto, não existem efetivamente enquanto direitos e políticas públicas, impossibilitando a experiência do prazer e da sublimação, ou seja, da ressignificação do sofrimento psíquico, causado pela repressão do desejo, por meio do deslocamento da pulsão.

Mediante essa realidade, o enfraquecimento dos laços sociais que decorrem da situação de violência, pobreza e desigualdade, tem no racismo mais um elemento de impedimento da manifestação do desejo e da possibilidade do direcionamento da energia libidinal para o desenvolvimento de relações sociais e afetivas não destrutivas. Desse modo, a droga pode se tornar uma forma de obter prazer de forma eficaz e inibir o sofrimento em meio a uma situação que se torna insustentável.

Câmara (2012) explica que dentre as várias maneiras de relacionarse com a droga, a transformação da substância como um objeto privilegiado 
e único torna-se possível. A chamada toxicomania se caracteriza por uma relação com a droga como um

[...] único objeto de satisfação, satisfação esta que, aliás, promove a ilusão de plenitude, de um gozo absoluto, sem falta. A falta é justamente o que esse sujeito adicto não tolera, e a droga passa, nessa relação, de objeto de satisfação para objeto que nomeia 0 Outro para este sujeito (CÂMARA, 2012, p. 55).

Por conta disso, a relação com a droga não pode ser considerada de sujeito-objeto de desejo, pois a satisfação é sempre parcial e libera uma quota de energia libidinal para continuar sempre em busca de outros objetos de desejo. O sujeito ao drogar-se renuncia a sua subjetividade e limita a consumação infinita de gozo. Logo "não se droga por desejo, antes, ele se droga para "esquecer dos problemas" - esquecer, por fim, sua angústia existencial" (CÂMARA, 2012, p. 55).

[...] Eu fico ansiosa 'pra' tomar o remédio 'pra' ansiedade e eu tenho que lutar contra isso. [...] Quando eu 'tô' muito ansiosa me dá vontade de tomar um monte pra passar porque é tão desesperador que você quer tomar um monte, que você quer que aquilo passe rápido. [...] É muito ruim você ficar ansiosa 'pra' tomar o remédio. (informação verbal) ${ }^{8}$

Direitos humanos [...] é a questão de você ter uma vida digna. [...] De viver e não sobreviver. (informação verbal) ${ }^{9}$

Os relatos dos adolescentes demonstram como o contexto de violência influencia na sua realidade de tal modo que a experiência da angústia é intensificada, conforme pode ser percebido ao falar dos direitos humanos e das drogas psiquiátricas. Silveira (2013) considera que o uso abusivo de álcool e outras drogas se dá como consequência de ausência de políticas públicas, ou seja, de acesso à saúde, moradia, educação e cidadania. O que a sociedade pauta atualmente é a droga sendo ocasionadora da miséria, pelo contrário, a droga é a consequência. A população periférica, uma vez privada dos seus direitos básicos, encontrase em uma situação de vulnerabilidade no encontro com a droga, ou seja,

\footnotetext{
${ }^{8}$ Relato do adolescente $N$., fala transcrita do cine-debate realizado no dia 23 de maio de 2019)

${ }^{9}$ Relato do adolescente L., fala transcrita do cine-debate realizado no dia 23 de maio de 2019).
} 
impossibilitadas de outras possibilidades de prazer, a droga torna-se um subterfúgio como forma de lidar com o mal-estar causado pela civilização.

As drogas psiquiátricas também são uma maneira de lidar com o sofrimento e o relato da adolescente ilustra, justamente, como o fenômeno da medicalização. Segundo Freitas e Amarante (2015), a medicalização consiste em transformar problemas de ordem social, afetivas, morais e culturais em doenças de ordem biológica, classificando tais comportamentos como transtornos ou distúrbios. Na fala da adolescente revela-se o limite da medicalização, em face da realidade vivida pelos jovens da periferia, uma vez que o alívio do sofrimento proporcionado pela substância pode se esgotar e gerar um novo fator de ansiedade, diante de uma sociedade que discrimina pelo racismo e pelo uso de drogas.

Desse modo, lidar coletivamente com esses temas, que pela angústia e sofrimento envolvidos tornam mais propício o desenvolvimento da dependência severa de drogas, pode ser potencialmente interessante para reduzir os danos da exposição à violência e ao consumo de drogas por adolescentes em regiões de conflito. Nesse sentido, propõe-se que a educação em direitos humanos, conforme aborda os temas relacionados aos preconceitos e estigmas que fomentam as violações, bem como as raízes da desigualdade e do autoritarismo de estado, que fazem perpetuar um estado de violência generalizada, pode ser apresentada como uma estratégia de redução de danos para ser realizada com coletivos de adolescentes nos espaços de educação formal e não-formal.

[...] Uma coisa que pode impactar bastante nisso, único jeito que seria de mudar isso, seria através da educação. (Adolescente L., fala transcrita do cine-documentário realizado no dia 23 de maio de 2019).

A educação em direitos humanos possibilitou aos jovens identificar e anunciar quais aspectos da sua realidade causam sofrimento e angústia. 0 relato do adolescente revela o papel central desta na mudança da realidade vivida, sendo vista como a única ferramenta possível para sua realização. Proporcionou também que conhecessem mais a fundo sua realidade, 
fortalecessem a subjetividade, desenvolvessem mais autonomia e criassem estratégias de enfrentamento ao sofrimento de acordo com o seu contexto socioeconômico.

\section{Considerações finais}

Observou-se ao longo dos seis encontros realizados com os adolescentes que seus direitos humanos são constantemente violados através do racismo estrutural, da desigualdade social, da violência policial ou do tráfico, o que impede o acesso a direitos básicos como educação, moradia digna e saúde de qualidade. Tal realidade acaba se tornando uma grande causadora de sofrimento psíquico e, por consequência, potencializa o envolvimento precoce e problemático com substâncias entorpecentes que possam amenizar os impactos que a violência gera em suas comunidades e subjetividades.

Foi possível compreender que trabalhar coletivamente e de forma pedagógica com os temas relacionados às angústias e sofrimentos, que tornam mais propício o desenvolvimento da dependência severa de álcool e outras drogas, pode ser potencialmente interessante para reduzir os danos da exposição à violência e ao consumo por adolescentes em regiões de conflito.

Os jovens que participaram das atividades demonstraram protagonismo e nível de reflexão e discussão muito elevados, expondo pelo diálogo as várias formas como são afetados pelo contexto de violação de direitos humanos, repressão e violência relacionada à política de "guerra às drogas." Apesar disso, o que mais chamou a atenção foi a atitude empoderada de muitos adolescentes, os quais conscientes de suas dificuldades e desafios se apresentaram como verdadeiros ativistas dos direitos humanos, ainda que não se entendessem desse modo.

As atividades de educação em direitos humanos realizadas apontaram justamente para a necessidade de trabalhar tais temas com eles, a fim de que possam compreender o sentido político de seu sofrimento, do fenômeno da drogadição e de como o Estado trata da situação. Compreende-se que, 
pela ampliação da consciência social e política, pode-se levar para a atuação de cada um na busca pela efetivação dos direitos humanos em suas comunidades e pode-se contribuir significativamente para reduzir os dados da violência e da drogadição entre adolescentes em territórios vulnerabilizados.

\section{Referências}

BRASIL. [Constituição (1988)]. Constituição da República Federativa do Brasil de 1988. Brasília, DF: Presidência da República. Disponível em: http://www.planalto.gov.br/ccivil_03/constituicao/constituicao.htm. Acesso em: 24. jun. 2019.

BRASIL. Departamento Penitenciário Nacional. Levantamento nacional de informações penitenciárias: Atualização - junho de 2017. Brasília, DF, 2017. Disponível em: http://depen.gov.br/DEPEN/depen/sisdepen/infopen/relatoriossinteticos/infopen-jun-2017-rev-12072019-0721.pdf. Acesso em: 24 jun. 2019.

BRASIL. Presidência da República. Lei no 10.216, de 6 de abril de 2001. Dispõe sobre a proteção e os direitos das pessoas portadoras de transtornos mentais e redireciona o modelo assistencial em saúde mental. Diário Oficial [da]

República Federativa do Brasil, Brasília, DF, abr. 2001. Disponível em: http://www.planalto.gov.br/ccivil_03/leis/leis_2001/l10216.htm. Acesso em: 23 mar. 2020.

CÂMARA, Gabriel. O papel da droga para o sujeito no mal-estar da civilização atual. Cógito, Salvador, n. 13, p. 53-57, 2012. Disponível em:

http://pepsic.bvsalud.org/scielo.php?script=sci_arttext\&pid=S1519-

94792012000100008. Acesso em: 26 maio 2019.

CFP - Conselho Federal de Psicologia. Relatório da inspeção nacional em comunidades terapêuticas. Brasília, DF, 2017. Disponível em:

https://site.cfp.org.br/wp-content/uploads/2018/06/Relat\%C3\%B3rio-daInspe $\%$ C3\%A7\%C3\%A3o-Nacional-em-Comunidades-Terap $\%$ C3\%AAuticas.pdf. Acesso em: 24 jun. 2019.

DAMASCENO, Marizete; ZANELLO, Valeska. Saúde mental e racismo contra negros: produção bibliográfica brasileira dos últimos quinze anos. Psicol. cienc. prof. [online]. Brasília, v. 38, n. 3, p. 450-464, 2018. Disponível em:

http://www.scielo.br/pdf/pcp/v38n3/1982-3703-pcp-38-3-0450.pdf. Acesso em: 15 abr. 2019.

FANON, Frantz. Pele negra, máscaras brancas. Salvador: EDUFBA, 2008.

FONTE, Carla. Comportamentos aditivos: conceito de droga, classificações de drogas e tipos de consumo. Revista da Faculdade de Ciências da Saúde, Porto, n. 3, p. 104-112, 2006. Disponível em:

https://bdigital.ufp.pt/bitstream/10284/533/1/104-112FCS2006-10.pdf. Acesso em: 14 jun. 2019.

FREITAS, Fernando; AMARANTE, Paulo. Medicalização em psiquiatria. Rio de Janeiro: Fiocruz, 2015. 
FREUD, Sigmund. O mal-estar na civilização. São Paulo: Companhia das Letras, 2011.

GEHRING, Marcos. Comunidade terapêutica: análise sócio demográfica, perspectivas, percepções e motivos para a recaída de residentes do esquadrão da vida de Bauru - SP. Revista do Laboratório de Estudos da Violência da UNESP/Marília. Marília, n. 14, p. 71-97, 2014. Disponível em: http://www2.marilia.unesp.br/revistas/index.php/levs/article/view/4211. Acesso em: 25 jun. 2019.

KARAM, Maria. Direitos humanos, laço social e drogas: por uma política solidária ao sofrimento humano. In: CONSELHO FEDERAL DE PSICOLOGIA. Drogas, direitos humanos e laço social. Brasília, DF: CFP, 2013. Disponível em: https://site.cfp.org.br/wp-content/uploads/2013/07/Drogas-Direitos-Humanos-eLaco-Social.pdf. Acesso em: 24 jun. 2019.

LANCETTI, Antonio. Contrafissura e plasticidade psíquica. São Paulo: Hucitec, 2015.

MACHADO, Letícia; BOARINI, Maria. Políticas sobre drogas no Brasil: a estratégia de redução de danos. Psicol. cienc. prof., Brasília, DF, v. 33, n. 3, p. 580-595, 2013. Disponível em: http://www.scielo.br/pdf/pcp/v33n3/v33n3a06.pdf. Acesso em: 23 mar. 2019.

NOGUEIRA FILHO, Durval Mazzei. A toxicomania entre a psicanálise e a psiquiatria. Revista Temas: Teoria e Prática do Psiquiatra, São Paulo, v. 32, jan./dez., 2002. Disponível em:

https://www.psiquiatriageral.com.br/farma/toxicomania.htm. Acesso em: 1 out. 2020.

QUEIROZ, Isabela. Os programas de redução de danos como espaços de exercício da cidadania dos usuários de drogas. Psicol. cienc. prof., Brasília, v. 21, n. 4, 2001. Disponível em:

http://pepsic.bvsalud.org/scielo.php?script=sci_arttext\&pid=S1414-

98932001000400002\&lng=pt\&nrm=iso\&tlng=pt. Acesso em: 23 mar. 2020.

SANCHEZ, Zila. Prevenção dos problemas relacionados ao uso de drogas. Brasília, 2017. Disponível em:

http://www.aberta.senad.gov.br/medias/original/201704/20170426-131721001.pdf. Acesso em: 24. jun. 2019.

SILVEIRA, Dartiu. Política atual de álcool e outras drogas e perspectivas. In: CONSELHO FEDERAL DE PSICOLOGIA. Drogas, direitos humanos e laço social. Brasília, DF: CFP, 2013. Disponível em: https://site.cfp.org.br/wpcontent/uploads/2013/07/Drogas-Direitos-Humanos-e-Laco-Social.pdf. Acesso em: 24 jun. 2019.

THIOLLENT, Michel. Metodologia da pesquisa-ação. 14. ed. São Paulo: Cortez, 2005.

ZAMORA, Maria. Desigualdade racial, racismo e seus efeitos. Fractal, Ver. Psicol., Niterói, v. 24, n. 3, p. 563-578, 2012. Disponível em:

http://www.scielo.br/pdf/fractal/v24n3/09.pdf. Acesso em: 14 abr. 2020. 